Article

\title{
Mitigating Global Methane Emissions Using Metal-Organic Framework Adsorbents
}

\author{
Eyas Mahmoud
}

Department of Chemical and Petroleum Engineering, United Arab Emirates University, Al Ain 15551, UAE; emahmoud@uaeu.ac.ae

Received: 12 October 2020; Accepted: 28 October 2020; Published: 31 October 2020

\begin{abstract}
Global emission of methane reached a record high in 2020. Furthermore, it is expected that methane emissions will continue to rise in the coming years despite the economic slowdown stemming from the coronavirus pandemic. Adsorbents can be used to reduce methane emissions. However, the question remains as to which adsorbents perform best for enhanced methane capture. In this work, it is demonstrated that metal-organic frameworks (MOFs) exhibited the best methane uptakes at 1 bar and $298 \mathrm{~K}$ from experiments as compared to tested carbonaceous materials, polymers, and zeolites. In addition, the adsorption entropy, an important thermodynamic property indicating adsorption capacity and kinetics, is determined on well-defined MOFs using a global predictive equation for porous materials. A correlation was used to describe the effect of translation and rotation of methane in the porous material for methane emission abatement. This information and the entropy of adsorption of methane on MOFs has not been reported before. The predicted results were compared to experimental data obtained from adsorption isotherms. Optimum isosteric heats were calculated by the Bhatia and Myers correlation. Finally, the pre-exponential factor of desorption is determined to aid in the design of materials for global methane emissions mitigation.
\end{abstract}

Keywords: metal-organic frameworks; methane; adsorption; entropy; kinetics; universal descriptor

\section{Introduction}

Global emission of methane reached a record high in 2020 [1,2]. It is expected that this rise in methane concentrations will continue in the coming years despite the economic slowdown stemming from the coronavirus pandemic [3]. In 2020, an active leak of sea-bed methane was discovered in Antarctica for the first time [4]. This is concerning because if warming continues other parts of the seafloor may also begin to leak methane and microbes may not quickly move in to prevent methane from rising to the atmosphere. In addition, in 2020, 300 tons of methane were released in the state of Florida in the United States of America (USA) [5]. Methane release is problematic because methane is a major greenhouse gas and a cause of global warming [6-8]. Methane is 100 times more potent than carbon dioxide as a greenhouse gas when it first goes into the atmosphere. Therefore, effective strategies to curb methane emissions are needed.

To tackle this problem, the environmental protection agency (EPA) in the USA initiated a voluntary methane program for the oil and natural gas industry [9]. In 2019, a consumers energy methane reduction plan was initiated to achieve net zero methane emissions by 2030 from a natural gas delivery system [10]. Recently it was reported that the European Union's greenhouse gas strategy failed to plug the hole associated with methane emissions [11].

What has worked to abate carbon dioxide emission is the use of the use of aqueous amine solutions as a technology to capture carbon dioxide as well as adsorption, which has been viewed as an alternative technology [12]. One adsorbent that was proposed to mitigate carbon dioxide emissions is metal-organic frameworks (MOFs) which were shown to be effective at adsorbing carbon dioxide in 
the presence of water [13-16]. MOFs are compounds comprised of metal nodes coordinated to organic ligands. The metal ions form a cluster known as the secondary building unit (SBU) which can be linked by organic compounds through reticular synthesis to form designed three-dimensional structures that can also be used for methane adsorption (Figure 1) [17,18]. Reticular synthesis allows for the molecular assembly of MOFs with a structure tailored for methane adsorption [19-23]. MOFs can be used as an adsorbent for methane abatement emissions technology. MOFs are a promising platform because their porosity can be adjusted and their chemistry can be tailored [24,25]. For gaseous fuel storage for natural gas vehicles (NGV), some MOFs have exhibited methane storage capabilities of more than $170 \mathrm{~cm}^{3}$ (STP = standard temperature and pressure equivalent volume of methane per volume of the adsorbent material: $\mathrm{T}=273.15 \mathrm{~K}, \mathrm{P}=101.325 \mathrm{kPa}$ ) $\mathrm{cm}^{-3}[19,26-28]$. This is due in part to the high surface areas of MOFs used for gaseous fuel storage [21,29,30]. However, for methane emission mitigation the process conditions are different as well as the material design approach as opposed to gaseous fuel storage for NGVs which necessitates the need for information regarding the adsorption capabilities of MOFs for this technology under different conditions.

(a)

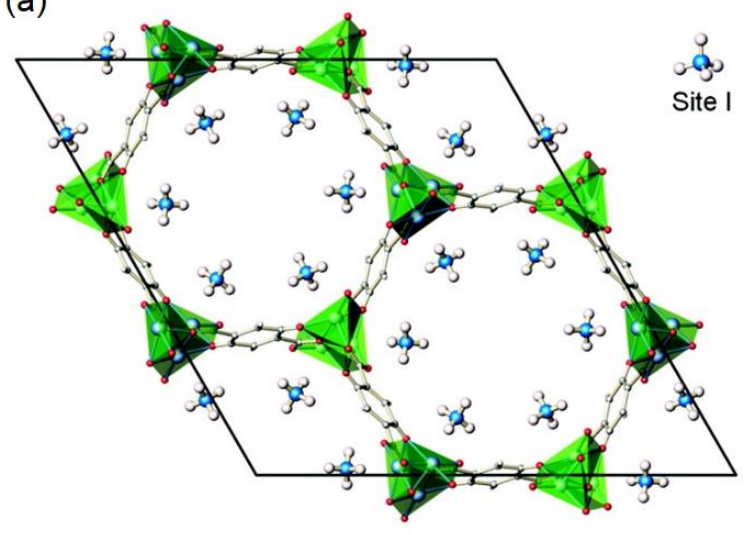

(b)

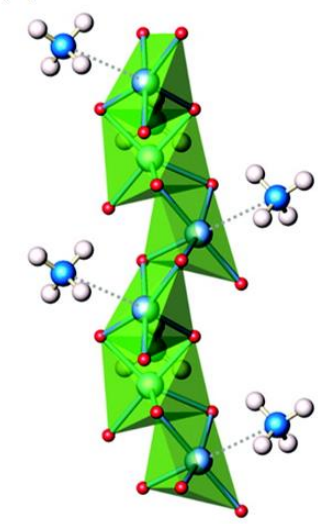

Figure 1. (a) $\mathrm{M}_{2}$ (dhtp) (dhtp = 2,5-dihydroxyterephthalate) crystal unit cell with adsorbed methane molecules on open metal site I. The location of sites was determined by neutron diffraction. (b) Metal oxide pyramids, organic linkers, and methane molecules. Adapted with permission from [31]. Copyright 2009 American Chemical Society.

In this work, the efficacy of metal-organic frameworks (MOFs) for methane capture at 1 bar and $298 \mathrm{~K}$ was assessed from experiments and compared to experimental results from other adsorbents such as carbonaceous materials, polymers, and zeolites. The entropy of adsorption can be used to determine the adsorption capacity of these materials as well as how fast they adsorb methane. Few measurements of the entropies of adsorption of methane on MOFs have been reported. Here, the entropy of adsorption of methane is determined in well-defined MOFs with nanoporosity and high surface area to assess the efficacy of MOFs to help curb global methane emissions. MOFs have shown exceptional performance for gas storage of key molecules such as methane and hydrogen which will power tomorrow's energy future [32-34]. It remains as a standing question of how to design these adsorbents to decrease methane global emissions. MOFs may be used to separate and adsorb methane to remove it from the atmosphere. They may also aid to decrease emissions from plants with methane leaks. In the case of adsorptive separation of methane from a stream rich in nitrogen, separation is difficult because the kinetic diameters of the two molecules are similar ( $3.8 \AA$ vs. $3.6 \AA$ ) and the design of the MOF becomes more important for the separation [35]. Because of the large number of MOF structures, more information regarding the functionality of the MOF and its pore size need to be determined. Furthermore, what is important to design is the interactions of methane and the MOF, which are measured in thermodynamics. Here, we demonstrate how thermodynamics applies to meet the needs of the future energy economy and atmospheric regulations with a focus on methane gas. Statistical mechanics is applied to representative MOF structures with the aim of providing insight into the 
design of these materials for methane emission abatement. The adsorption entropy is determined on well-defined MOFs using global predictive equation for porous materials. A correlation is used to describe the effect of translation and rotation of methane in the porous material for methane emission abatement. This information and the entropy of adsorption of methane on MOFs has not been reported before. New correlations for methane using the Bhatia and Myers correlation are also developed and applied in this work [36]. Finally, how fast methane can be desorbed from these MOFs is determined for this application.

\section{Materials and Methods}

MOFs with experimentally determined crystal structures, densities, pore volumes, methane isosteric heats of adsorption $\left(\mathrm{Q}_{\mathrm{st}}\right)$, and methane uptakes at $298 \mathrm{~K}$ were evaluated for methane capture at low pressures (around 1 bar). When uptakes were not available, they were determined from adsorption isotherms obtained from experiments. A universal descriptor was utilized to calculate the entropy of adsorption [37]. The entropy change of adsorption of methane on a slab was approximated using Campbell and Sellers estimate [38]:

$$
-\Delta \mathrm{S}_{\mathrm{ads}}(\mathrm{T})=0.3 \mathrm{~S}_{\mathrm{gas}}(\mathrm{T})+3.3 \mathrm{R}
$$

For methane adsorption to mitigate global methane emission levels, the molecule gains energy that is measured by a change in enthalpy that is associated with interactions with the surface $\left(\Delta \mathrm{H}^{\circ}\right.$ ads $)$. However, the methane molecule will have restricted motion on the surface as compared to the gas phase which results in a loss of entropy:

$$
\Delta \mathrm{G}^{\circ}{ }_{\text {ads }}=\Delta \mathrm{H}^{\circ}{ }_{\text {ads }}-\mathrm{T} \Delta \mathrm{S}^{\circ}{ }_{\text {ads }}
$$

For associative adsorption of methane, the process is not activated and reversible. Adsorption of methane from the gas phase leads to a transition state (TS) of methane at a particular distance such that one degree of translational freedom is lost. For MOFs whose surfaces are curved, adsorbed methane was expected to be further restricted. This further restriction was expected to result in a further loss of entropy for the adsorbed state which makes the process less favorable by resulting in a larger Gibbs free energy of adsorption. Ultimately, thermodynamics suggests that this effect can be mitigated by decreasing the enthalpy of adsorption by designing the MOF to have more favorable interactions with methane. This can be achieved by reticular synthesis to fine tune the pore architecture [39], pore spacing [40], linker [41,42], functional groups [43,44], and hydrophobicity [45,46], and the nature of ligands $[47,48]$ of the MOF. These features would result in more favorable enthalpies of adsorption which result from van der Waals forces were considered for MOFs.

The Sackur-Tetrode equation was used to determine the translation entropy of methane molecules when they behaved as immobile adsorbents to calculate the entropy lost upon adsorption [49-51]:

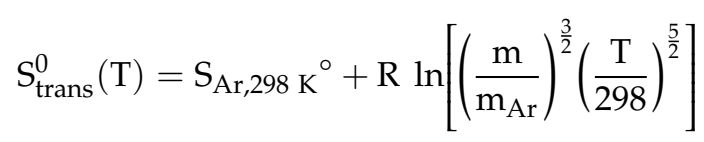

$\mathrm{S}_{\mathrm{Ar}, 298 \mathrm{~K}^{\circ}}$ is the standard entropy of argon at standard pressure of $1 \mathrm{bar}$ and temperature of $298 \mathrm{~K}$ in the gas phase. At these conditions, its value is $154.8 \mathrm{~J} \mathrm{~mol}^{-1} \mathrm{~K}^{-1}$. $\mathrm{R}$ is the universal gas constant and has a value of $8.314 \mathrm{~J} \mathrm{~mol}^{-1} \mathrm{~K}^{-1}$. $\mathrm{m}$ is the molecular weight of methane which is $16.04 \mathrm{~g} / \mathrm{mol}$ and $\mathrm{m}_{\mathrm{Ar}}$ is the molecular weight of argon $39.948 \mathrm{~g} / \mathrm{mol}$. Finally, $\mathrm{T}$ is the temperature in units of Kelvin at which the translational entropy was calculated. When adsorbed methane is not immobile and has one degree of translational motion, the entropy was calculated by $S_{\text {trans }} / 3$.

To increase the accuracy of the approximation, rotational entropy upon adsorption of methane was also considered on MOFs. This accounted for rotation of methane parallel to the pore surface, 
but does not include methane rotation perpendicular to the surface. The entropy loss upon adsorption was calculated by:

$$
\Delta S^{\circ} \text { ads }=\Delta S^{\circ}{ }_{1 \mathrm{D}, \operatorname{tran}}+\Delta \mathrm{S}^{\circ}{ }_{1 \mathrm{D}, \text { rot }}
$$

The entropy of adsorption in three-dimensions was determined by:

$$
\mathrm{S}_{\text {rot }}=\mathrm{R}\left\{\ln \left[\frac{\sqrt{\pi \mathrm{I}_{\mathrm{A}} \mathrm{I}_{\mathrm{B}} \mathrm{I}_{\mathrm{C}}}}{\sigma}\left(\frac{8 \pi^{2} \mathrm{k}_{\mathrm{B}} \mathrm{T}}{\mathrm{h}^{2}}\right)^{\frac{3}{2}}\right]+\frac{3}{2}\right\}
$$

where $\mathrm{I}_{\mathrm{A}}, \mathrm{I}_{\mathrm{B}}$, and $\mathrm{I}_{\mathrm{C}}$ are principle moments of inertia and $\sigma$ is the external symmetry number. The external symmetry number is 12 for methane. For methane, the principle moments of inertia are equal. The two constants present in the equation, $\mathrm{k}_{\mathrm{B}}$ and $\mathrm{h}$, are Boltzmann and Planck's constants $1.38064852 \times 10^{-23} \mathrm{~m}^{2} \mathrm{~kg} \mathrm{~s}^{-2} \mathrm{~K}^{-1}$ and $6.62607004 \times 10^{-34} \mathrm{~m}^{2} \mathrm{~kg} \mathrm{~s}^{-1}$. The entropy of adsorption was divided into translational and rotational components:

$$
\Delta S^{\circ}{ }_{a d s, C H}, j=F_{\text {trans }, j} S_{1 D, t r a n}^{\circ}+F_{\text {rot }, j} S_{\text {rot }, i}{ }^{\circ}
$$

where $F_{\text {trans,j }}$ and $F_{\text {rot,j }}$ represent fraction of entropy lost and $j$ represents the MOF framework. These fractional loses can be obtained from experimental data. The fractional loses of the entropy of adsorption was divided into translational and rotational components:

$$
F_{\text {rot }, j}=F_{\text {rot,slab }}+F_{\text {rot }, \text { conf }, j}
$$

It was postulated that the fraction of rotational entropy lost is a function of the occupiable volume $\left(\mathrm{V}_{\text {occ, }}\right)$ in the MOF framework. The rotational configuration fractional loss was calculated using Equation (9). The critical volume used was $127.3 \AA$.

$$
\begin{gathered}
\mathrm{F}_{\text {rot }, \text { conf }, \mathrm{j}}=\mathrm{f}\left(\mathrm{V}_{\text {occ }, j}\right) \\
\mathrm{F}_{\text {rot,conf }, \mathrm{j}}=\frac{1}{7}\left[\left(1-\frac{\mathrm{V}_{\text {critical }}}{2 \mathrm{~V}_{\text {occ }, j}}\right)^{-3}-1\right]
\end{gathered}
$$

The entropy of adsorption of methane on MOFs was calculated using Equation (10):

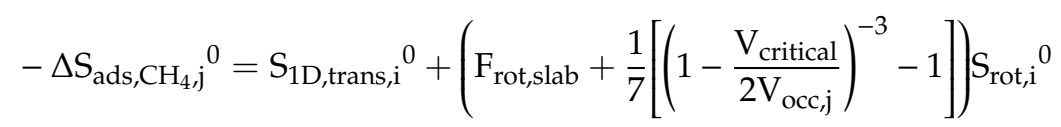

Whereas Bhatia and Myers introduced a new thermodynamic relation for optimal $Q_{\text {st }}$ which was used to determine the maximum delivery between a storage pressure $P_{1}$ and the discharge pressure $P_{2}$ at a given temperature $\mathrm{T}[36]$ :

$$
\mathrm{Q}_{\mathrm{st}}(\text { Optimal })=-\mathrm{T} \Delta \mathrm{S}_{0}-\frac{\mathrm{RT}}{2 \ln \left(\frac{\mathrm{P}_{1} \mathrm{P}_{2}}{\mathrm{P}_{0}^{2}}\right)}
$$

where $Q_{s t}$ is the average heat of adsorption between $P_{1}$ and $P_{2}, \Delta S_{0}$ is the entropy change relative to the standard pressure $\mathrm{P}_{0}(1 \mathrm{bar})$ and $\mathrm{R}$ is the ideal gas constant.

Differential enthalpies and entropies of desorption were calculated using the ClausiusClapeyron equation:

$$
\ln \left(\mathrm{p}_{\mathrm{q}}\right)=\left(\frac{\Delta \mathrm{h}_{\mathrm{ads}}}{\mathrm{T}}\right)\left(\frac{1}{\mathrm{~T}}\right)+\left(\frac{-\Delta \mathrm{S}_{\mathrm{ads}}}{\mathrm{R}}\right)
$$


q represents the loading. The kinetics of desorption were evaluated using:

$$
\mathrm{v}_{\text {des }}=\frac{\mathrm{k}_{\mathrm{B}} \mathrm{T}}{\mathrm{h}} \mathrm{e}^{\frac{\Delta \mathrm{S}_{\mathrm{TS}, \text { des }}}{\mathrm{R}}}=\frac{\mathrm{k}_{\mathrm{B}} \mathrm{T}}{\mathrm{h}} \mathrm{e}^{\frac{-\Delta \mathrm{S}_{1 \mathrm{D} \text {,trans }}-\Delta \mathrm{S}_{\text {ads }}}{\mathrm{R}}}
$$

$\Delta \mathrm{S}_{\mathrm{TS} \text {,des }}$ is the entropy change associated with the adsorbed methane molecule approaching the transition state of desorption:

$$
\mathrm{v}_{\text {des }}=\frac{\mathrm{k}_{\mathrm{B}} \mathrm{T}}{\mathrm{h}} \mathrm{e}^{\frac{\Delta \mathrm{S}_{\mathrm{TS}, \mathrm{des}}}{\mathrm{R}}}=\frac{\mathrm{k}_{\mathrm{B}} \mathrm{T}}{\mathrm{h}} \mathrm{e}^{\frac{-\Delta \mathrm{S}_{1 \mathrm{D}, \text { trans }}-\Delta \mathrm{S}_{\mathrm{ads}}}{\mathrm{R}}}
$$

The preexponential factor for desorption was also defined using:

$$
\mathrm{v}_{\mathrm{des}, \mathrm{CH}_{4}, \mathrm{j}}=\frac{\mathrm{k}_{\mathrm{B}} \mathrm{T}}{\mathrm{h}} \mathrm{e}^{\frac{\mathrm{F}_{\mathrm{rot}, \mathrm{j}} \mathrm{S}_{\mathrm{rot}, \mathrm{CH}}}{\mathrm{R}}}
$$

\section{Results}

To investigate the effectiveness of MOFs as adsorbents for global methane mitigation, methane uptakes were determined from experiments. The textural properties and methane uptakes of MOFs at various conditions including $298 \mathrm{~K}$ and 1 bar are provided in Table 1.

ATC-Cu exhibited the best methane uptake of $2.8 \mathrm{mmol} \mathrm{g}^{-1}$ at $298 \mathrm{~K}$ and 1 bar. This is followed by Cu-tbo-MOF-5 which exhibited a methane uptake of $1.29 \mathrm{mmol} \mathrm{g}^{-1}$ at $298 \mathrm{~K}$ and 1 bar and HKUST-1 which had an uptake of $1.0 \mathrm{mmol} \mathrm{g}^{-1}$ at $298 \mathrm{~K}$ and 1 bar. In comparison, the methane uptake of carbonaceous materials such as KUA41751, KUA31751, KUA21751, and KUA51751 were less than $1.5 \mathrm{mmol} \mathrm{g}^{-1}$ at 1 bar and $298 \mathrm{~K}$ (Table 2) [52]. HSAC-19, HSAC-21, HSAC-23, and HSAC 30, which are high surface area activated carbons reported to have high methane uptakes at low pressure, possessed methane uptakes of less than $2.7 \mathrm{wt} . \%$ at $298 \mathrm{~K}$ and 1 bar [53]. This corresponds to less than $1.7 \mathrm{mmol} \mathrm{g}^{-1}$ of methane adsorbed. Poly ( $p$-DCX) porous coordination polymer exhibited a methane uptake of less than $1 \mathrm{mmol} \mathrm{g}^{-1}$ at $298 \mathrm{~K}$ and 1 bar [54]. Zeolites such as NaX and CaX exhibited a methane uptake of less than $0.75 \mathrm{mmol} \mathrm{g}^{-1}$ at $303 \mathrm{~K}$ and 1 bar [55]. Based on these results, MOFs exhibited the best methane uptakes at 1 bar and $298 \mathrm{~K}$ from the materials investigated and are effective adsorbents.

\begin{tabular}{|c|c|c|c|c|c|c|c|c|}
\hline MOF & $\begin{array}{c}V_{\mathbf{P}} \\
\left(\mathrm{cm}^{3} \mathrm{~g}^{-1}\right)^{a}\end{array}$ & $\begin{array}{c}\text { BET Surface } \\
\text { Area }\left(\mathrm{m}^{2} \mathrm{~g}^{-1}\right)\end{array}$ & $\begin{array}{l}\text { Lang. Surface } \\
\text { Area }\left(\mathrm{m}^{2} \mathrm{~g}^{-1}\right)\end{array}$ & $\mathbf{T}(\mathrm{K})$ & $P($ bar) & $\begin{array}{l}\text { Methane Uptake } \\
\left(\mathrm{mmol} \mathrm{g}^{-1}\right)\end{array}$ & $\mathrm{Q}_{\mathrm{st}}\left(\mathrm{kJ} \mathrm{mol}^{-1}\right)$ & Ref. \\
\hline UTSA-110a & 1.263 & 3241 & - & 273.15 & 1 & - & 14.5 & {$[56]$} \\
\hline HKUST-1 & 0.78 & 1850 & - & 298 & 1 & $1.0^{\mathrm{c}}$ & 17 & [57] \\
\hline ATC-Cu & 0.23 & 600 & - & 298 & 1 & $2.8^{\mathrm{c}}$ & 26.8 & [35] \\
\hline NU-1501-Al & - & 7310 & - & 270 & 1 & - & - & [58] \\
\hline Al-soc-MOF-1 & 2.3 & 5585 & - & 298 & 1 & $0.33^{c}$ & 10.5 & [59] \\
\hline PCN-14 & 0.85 & 2170 & - & 298 & 1 & - & 17.6 & [32] \\
\hline NJU-Bai 43 & 1.22 & 3090 & - & 298 & 1 & $0.20^{\mathrm{c}}$ & 14.45 & [60] \\
\hline PCN-61 & 1.36 & 3000 & - & 298 & 1 & - & - & [44] \\
\hline MOF-950 & 1.3 & 3440 & - & 298 & 1 & $0.38^{c}$ & 11.9 & [61] \\
\hline NJU-Bai 42 & 1.07 & 2830 & - & 298 & 1 & $0.80^{\mathrm{c}}$ & 14.49 & [60] \\
\hline $\mathrm{Fe}(\mathrm{bpd})$ & - & - & - & 298 & 1 & $0.1^{c}$ & - & [62] \\
\hline NU-135 & 1.02 & 2530 & - & 298 & 1 & $0.9^{c}$ & 16.6 & [63] \\
\hline NU-125 & 1.29 & 3120 & - & 298 & 1 & - & 15.5 & [64] \\
\hline ZJU-25 & 1.183 & 2124 & - & 300 & 1 & - & 15.1 & [64] \\
\hline MOF-519 & 0.938 & 2400 & - & 298 & 1 & $0.49^{c}$ & 14.6 & [65] \\
\hline MOF-5 & 1.4 & - & - & 298 & 1 & - & 12.3 & [66] \\
\hline NJU-Bai 19 & 1.063 & 2803 & - & 298 & 1 & $0.85^{c}$ & 14.8 & [67] \\
\hline Cu-tbo-MOF-5 & 0.595 & 3971 & - & 298 & 1 & $1.29^{c}$ & 20.4 & [68] \\
\hline MOF-905- $\mathrm{Me}_{2}$ & - & - & - & 298 & 1 & $0.47^{b}$ & - & [61] \\
\hline MOF-905 & 1.34 & 3490 & 3770 & 298 & 1 & $0.33^{b}$ & 11.7 & [61] \\
\hline MOF-905-Naph & 1.25 & 3310 & 3540 & 298 & 1 & $0.45^{b}$ & 11.3 & [61] \\
\hline MOF-905-NO ${ }_{2}$ & 1.29 & 3380 & 3600 & 298 & 1 & $0.403^{b}$ & 10.7 & [61] \\
\hline NJU-Bai-41 & 0.92 & 2370 & - & 298 & 1 & $0.969^{\mathrm{c}}$ & 17.77 & [60] \\
\hline $\mathrm{Al}_{4}(\mathrm{OH})_{8}(\mathrm{btec}) \mathrm{MIL}-120$ & 0.11 & 308 & 432 & 303 & 10 & $1.7^{\mathrm{d}}$ & 27 & [69] \\
\hline $\mathrm{Cu}_{2}(\mathrm{tdm})[\mathrm{PCN}-26]$ & 0.84 & 1854 & 2545 & 298 & 1.07 & $1.1^{\mathrm{d}}$ & - & {$[70]$} \\
\hline $\mathrm{Cu}_{2}(\mathrm{ebtc})$ & - & 1852 & 2844 & 273 & 1 & $0.6^{\mathrm{c}}$ & - & [71] \\
\hline
\end{tabular}

Table 1. Pore volume, BET surface area, $\mathrm{Q}_{\text {st }}$, and methane uptake of selected metal-organic frameworks (MOFs). 
Table 1. Cont.

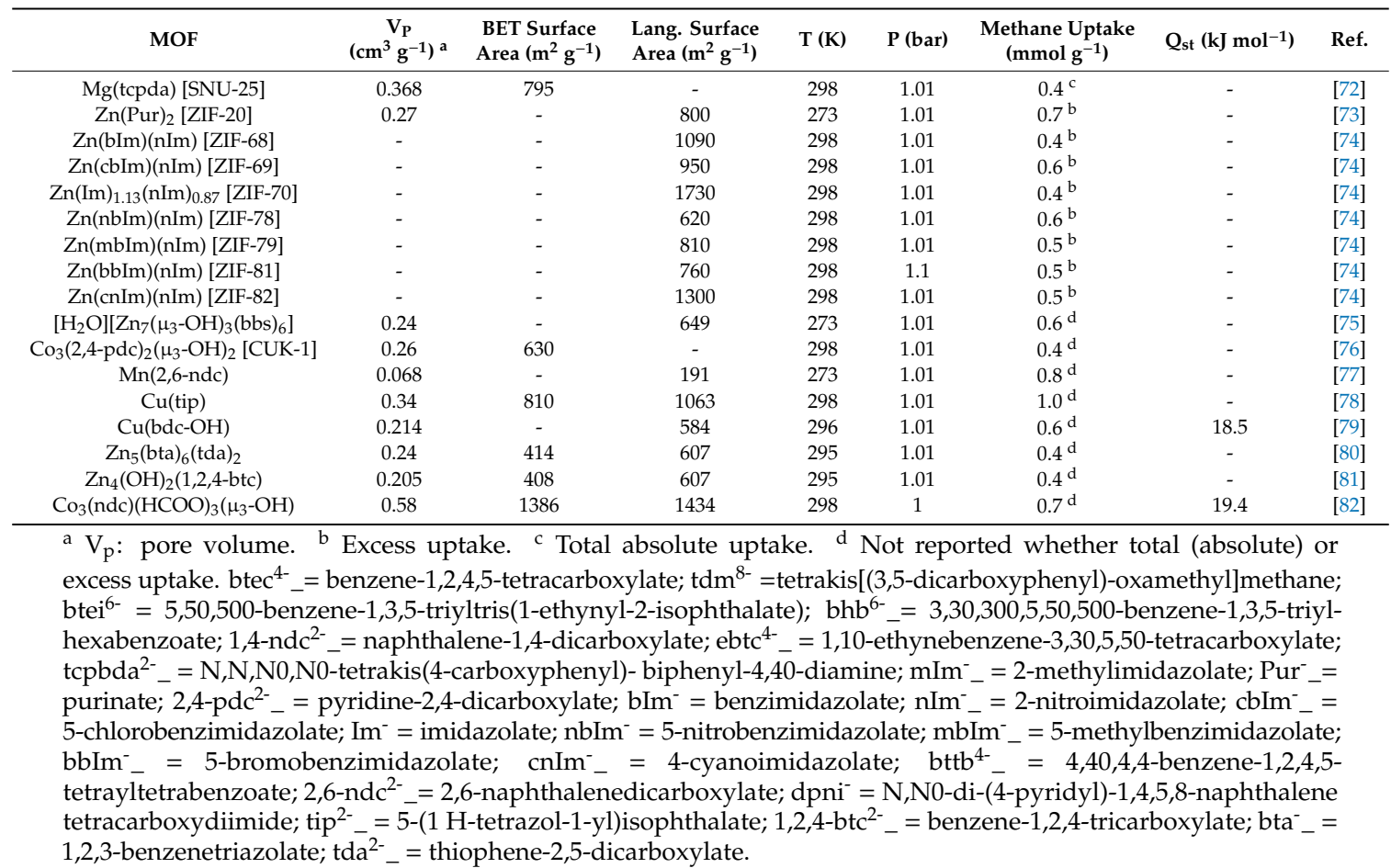

Table 2. Pore volume, surface area, $\mathrm{Q}_{\text {st }}$, and methane uptake of selected carbons, zeolites, and porous organic polymers.

\begin{tabular}{|c|c|c|c|c|c|c|c|}
\hline Adsorbent & $\begin{array}{c}V_{P} \\
\left(\mathrm{~cm}^{3} \mathrm{~g}^{-1}\right)^{a}\end{array}$ & $\begin{array}{l}\text { BET Surface Area } \\
\left(\mathrm{m}^{2} \mathrm{~g}^{-1}\right)\end{array}$ & $\begin{array}{c}\text { Methane } \\
\text { Uptake }\left(\mathrm{mmol} \mathrm{g}^{-1}\right)\end{array}$ & $\mathrm{T}(\mathbf{K})$ & P (bar) & $\mathrm{Q}_{\mathrm{st}}\left(\mathrm{kJ} \mathrm{mol}^{-1}\right)$ & Ref. \\
\hline \multicolumn{8}{|l|}{ Carbonaceous materials } \\
\hline MW-CNTs@JUC32-2 & - & 146 & $0.75^{c}$ & 273 & 1 & 23.9 & [83] \\
\hline KUA51751 & 1.48 & 3350 & $1.34^{\mathrm{c}}$ & 298 & 1 & - & [84] \\
\hline KUB41701 & 0.92 & 2123 & $1.32^{\mathrm{c}}$ & 298 & 1 & - & [84] \\
\hline Maxsorb-A & 1.38 & 3100 & $1.28^{\mathrm{c}}$ & 298 & 1 & - & [84] \\
\hline FELT 1 & 0.81 & 1741 & $1.34^{\mathrm{c}}$ & 298 & 1 & - & [84] \\
\hline LFC14 & 0.23 & 520 & $1.15^{\mathrm{c}}$ & 298 & 1 & - & [84] \\
\hline LFC30 & 0.41 & 930 & $1.22^{\mathrm{C}}$ & 298 & 1 & - & [84] \\
\hline CFC19 & 0.32 & 647 & 1.05 & 298 & 1 & - & [84] \\
\hline CFC54 & 0.84 & 1859 & 1.09 & 298 & 1 & - & [84] \\
\hline CFC74 & 0.92 & 2862 & 1.15 & 298 & 1 & - & [84] \\
\hline \multicolumn{8}{|l|}{ Zeolites } \\
\hline $\mathrm{NaX}$ & 0.220 & 534 & $0.65^{c}$ & 303 & 1 & 20.1 & [55] \\
\hline $\mathrm{NaA}$ & - & 473 & $0.65^{c}$ & 303 & 1 & - & [55] \\
\hline $\mathrm{CaA}$ & 0.150 & 440 & $0.59^{c}$ & 303 & 1 & 29.0 & [55] \\
\hline \multicolumn{8}{|l|}{ Polymers } \\
\hline $\begin{array}{c}p \text {-Dichloroxylene } \\
(p \text {-DCX) }\end{array}$ & 0.36 & 1307 & $0.73^{c}$ & 298 & 1 & 20.8 & [54] \\
\hline $\mathrm{BCMBP} / p-\mathrm{DCX}$ & 0.54 & 1904 & $0.72^{\mathrm{c}}$ & 298 & 1 & - & [54] \\
\hline
\end{tabular}

\footnotetext{
${ }^{\mathrm{a}} \mathrm{V}_{\mathrm{p}}$ : pore volume. ${ }^{\mathrm{c}}$ Total absolute uptake.
}

Entropies of adsorption on MOFs were determined. Particular emphasis was paid to quantify the effect of methane confinement in MOFs. Some MOFs were investigated for this application were HKUST-1, NU-125, PCN-46, PCN-61, SNU-30, SNU-50, UTSA-20, MOF-5, MOF-905, and MOF-519 [40,61,64,65]. Adsorption entropies were calculated to determine the equilibrium adsorption, maximum uptake of methane at process conditions, and rate constants for the methane adsorption process. Important characteristics of MOFs including open metal-sites allow for methane adsorption from the gas phase. The entropy of methane gas at $298 \mathrm{~K}$ is $188.66 \mathrm{~J} \mathrm{~mol}^{-1} \mathrm{~K}^{-1}$. The Sackur-Tetrode equation was used to estimate the entropy of translation of methane at $298 \mathrm{~K}$ to be $143.420 \mathrm{~J} \mathrm{~mol}^{-1} \mathrm{~K}^{-1}$ (Figure 2). 
The rotational entropy of methane gas at $298 \mathrm{~K}$ is $40.74 \mathrm{~J} \mathrm{~mol}^{-1} \mathrm{~K}^{-1}$. For one-dimensional translation, the entropy of methane at $298 \mathrm{~K}$ is $47.81 \mathrm{~J} \mathrm{~mol}^{-1} \mathrm{~K}^{-1}$.

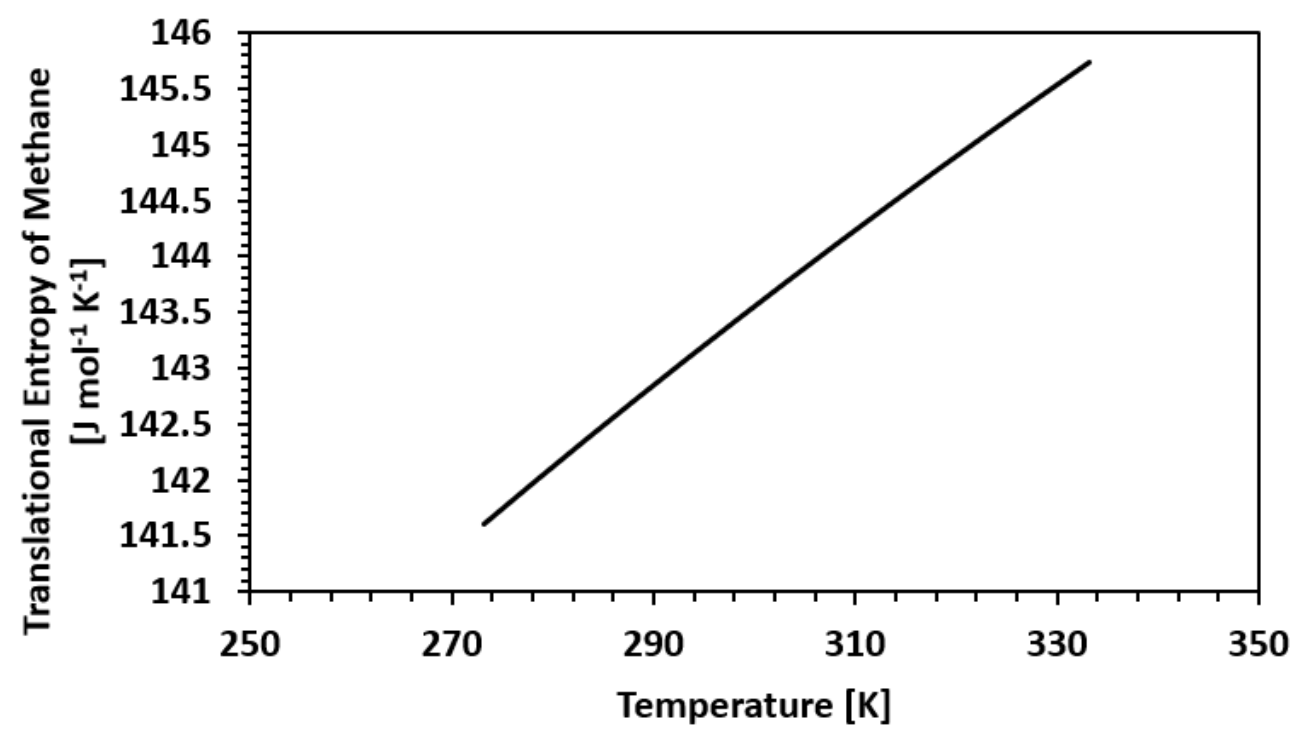

Figure 2. Methane translational entropy as a function of temperature determined using the Sackur Tetrode equation.

The calculated methane entropy change of adsorption on a slab based was determined using Campbell and Sellers estimate to be $-84.0342 \mathrm{~J} \mathrm{~mol}^{-1} \mathrm{~K}^{-1}$ [38]. This value provides an estimate of what degree of interaction is required for an enthalpic energy change for an effective adsorbent for methane for global methane emissions abatement. In Figure 3, the entropy of methane gas is compared to the entropy of adsorbed methane obtained by using the equation provided by Campbell and Sellers (Equation (1)) and compared to some experimental data [38].

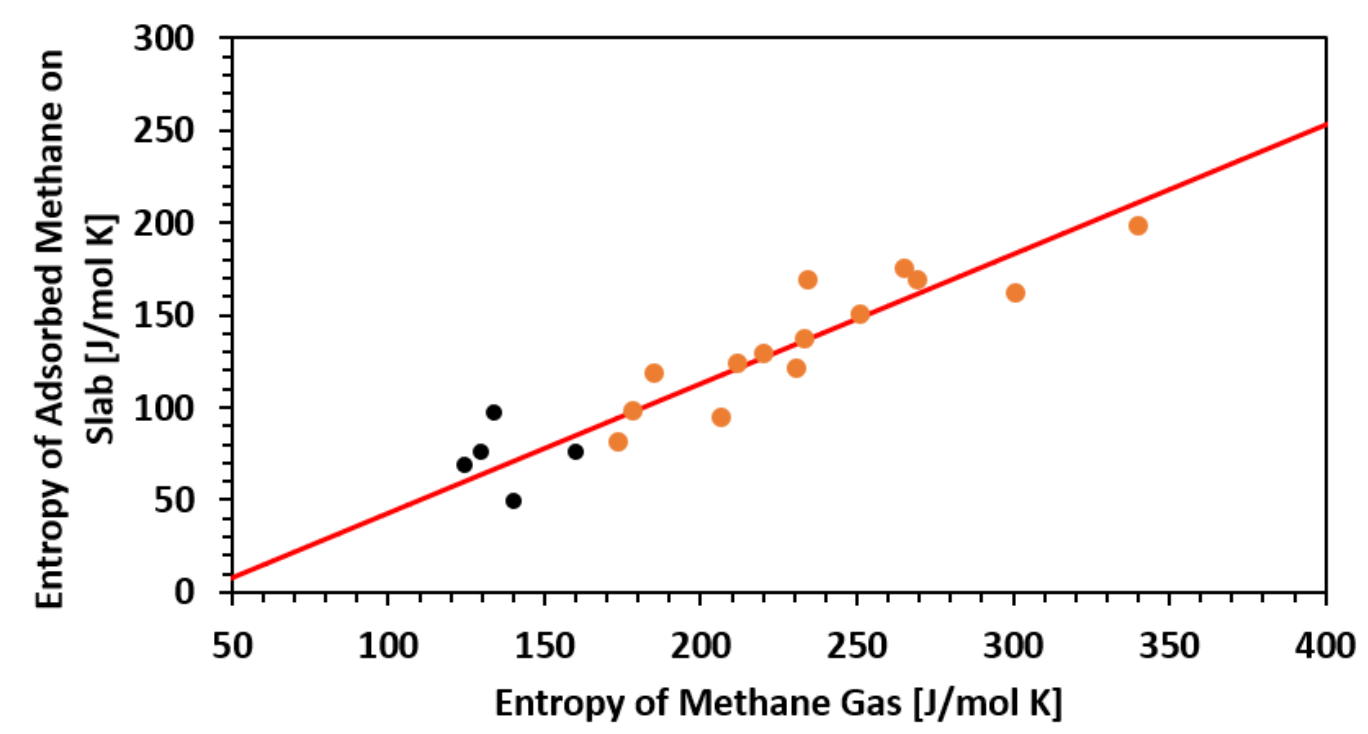

Figure 3. Entropy of adsorbed methane on $\mathrm{MgO}$ (100), Mg (100), PdO (101), Pt (111), and C (0001) surfaces from temperature programmed desorption (TPD) data analysis and adsorption data plotted against the entropy of methane gas represented by black data points. Orange point represent data determined from experiments associated with $C_{2}-C_{10}$ alkane adsorption on slabs [38]. 
To further get insight into how to design MOFs for methane emission mitigation, the translation and rotational components of the gas phase entropy that were lost upon methane adsorption were estimated. Two degrees of translational freedom are preserved, which are associated with methane travelling through the porous network. On the other hand, rotational freedom is more restricted particularly in the case where the pore diameter shrinks. This results in the hindered rotation of methane molecules in the one-dimensional nanochannel that was observed for a porous coordination polymer [85]. The rotational freedom lost depends on the framework of the porous material. This is because the degree of confinement of the methane molecule is affected by the pore size and pore size distribution of the material. This in turn affects the adsorbed state. Therefore, the degree of rotational freedom lost is important and is related to the pore architecture of the MOF, which allows for the better design of MOFs for this application. In Table 3, the physical characteristics of MOF frameworks are provided.

Table 3. Physical characteristics of MOF frameworks [86].

\begin{tabular}{cccc}
\hline Framework & $\begin{array}{c}\text { Largest Cavity } \\
\text { Diameter (A) }\end{array}$ & $\begin{array}{c}\text { Void Fraction of Accessible } \\
\text { Probe-Occupiable Pore Volume }\end{array}$ & Ref. \\
\hline HKUST-1 & 13.14982 & 0.67 & {$[57]$} \\
DUT-13 & 18.4908 & 0.81 & {$[85]$} \\
NU-125 & 19.37323 & 0.73 & {$[64]$} \\
PCN-46 & 12.05622 & 0.72 & {$[87]$} \\
PCN-61 & 18.70668 & 0.75 & {$[44]$} \\
SNU-30 & 14.9209 & 0.83 & {$[88]$} \\
UTSA-20 & 9.95246 & 0.57 & {$[40]$} \\
\hline
\end{tabular}

An important parameter which is known as a physical descriptor was used to predict confinement effects. Occupiable volume $\left(\mathrm{V}_{\text {occ }}\right)$ was used as the descriptor. $V_{\text {occ }}$ is defined as the number of spheres with a diameter of $2.8 \AA$ that can be packed into the framework of the porous material [37]. In Figure 4, the rotational degrees of freedom lost by methane due to confinement was related to $V_{\text {occ. }} F_{\text {rot,conf }}$ or rotational degrees of freedom lost due to confinement approaches zero with larger occupiable volumes. In Figure 5, the entropy change of adsorption was plotted against $V_{\text {occ }}$.

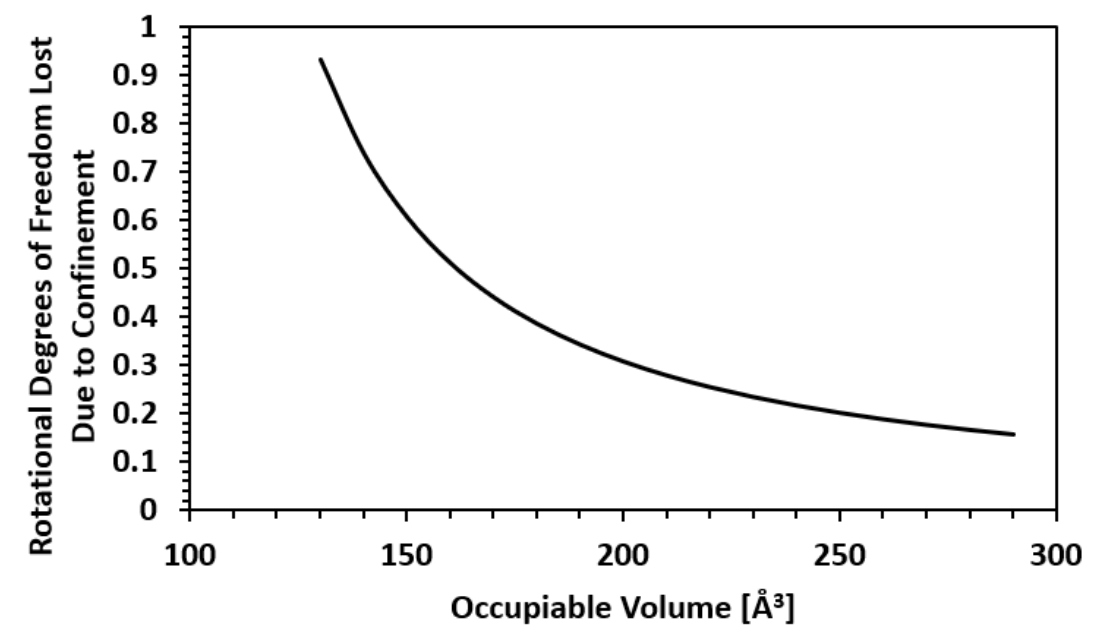

Figure 4. Calculated rotational degrees of freedom lost upon adsorption with varying occupiable volume $\left(\mathrm{V}_{\mathrm{occ}}\right)$. 


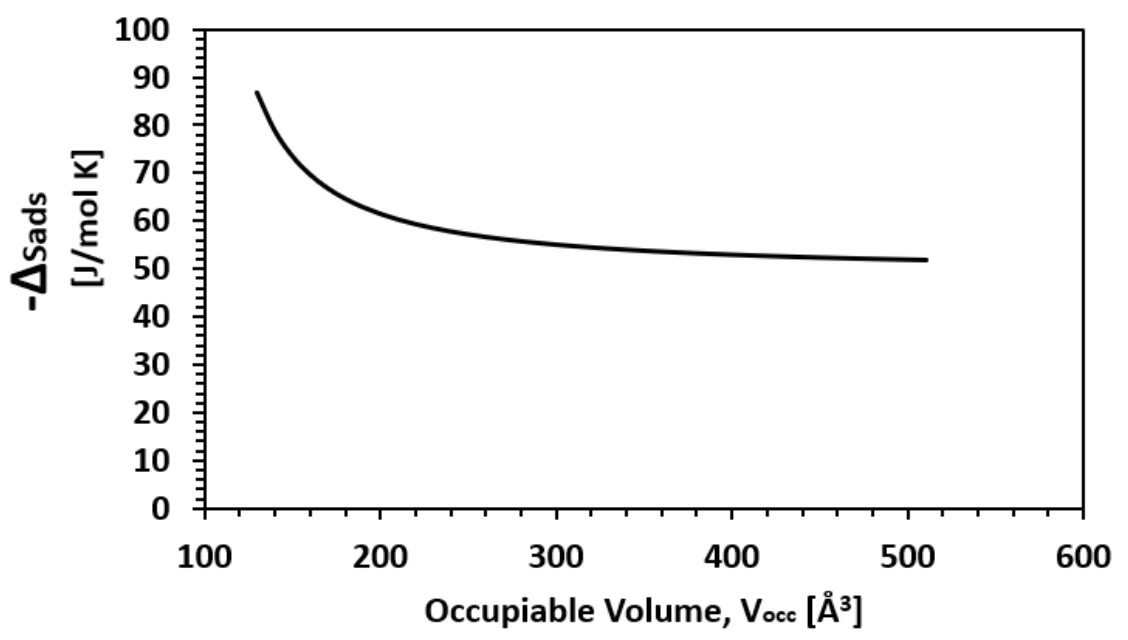

Figure 5. $-\Delta$ Sads vs. $V_{\text {occ. }}$ The entropy change of methane associated with adsorption on a porous material for various occupiable volumes.

To verify the predictions made using the universal descriptor used to determine methane entropies, a comparison of calculated entropy changes was made with experimental data. Entropies from experimental data were calculated using the Clausius-Clapeyron Equation (12) at constant loading (Figure 6). The calculated methane enthalpy and entropy of adsorption from adsorption experiments are shown in Table 4 . The entropy changes of adsorption determined from experimental data were found to be on the same order of magnitude as those determined using the universal descriptor.

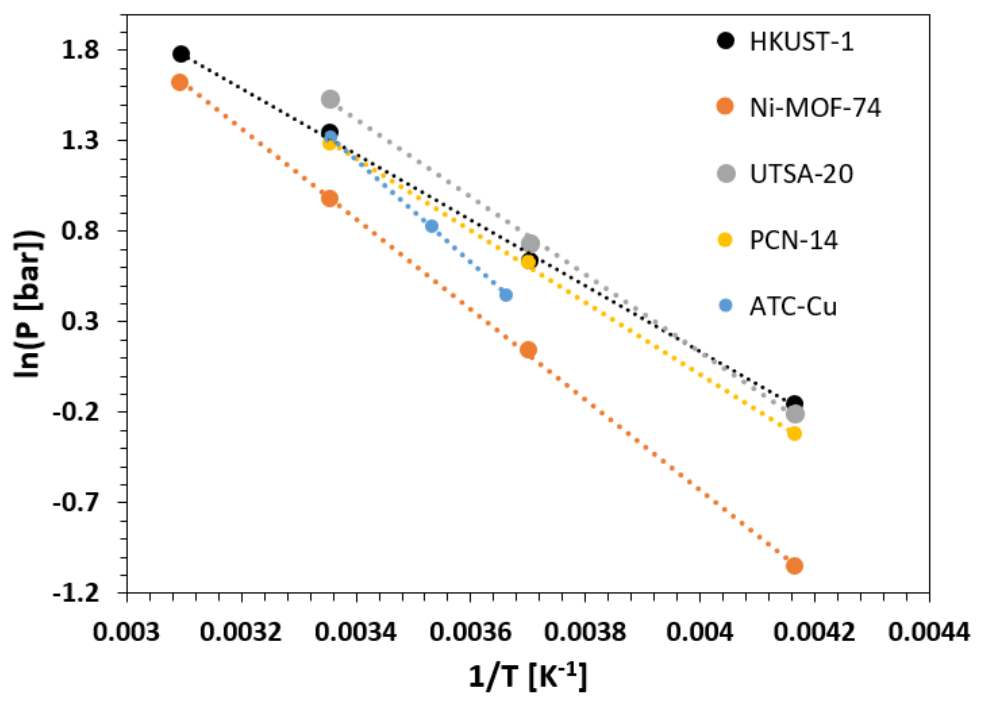

Figure 6. Plot of the natural log of the pressure in bar against inverse temperature in units of kelvin for various MOFs and the associated linear regressions of the experimental data points [32]. $R^{2}$ for each fitted linear line is greater than 0.99 .

Table 4. Calculated enthalpy and entropy of adsorption of methane on MOFs from adsorption experiments determined using the Clausius-Clapeyron equation at constant loading.

\begin{tabular}{cccc}
\hline Framework & $-\Delta \mathbf{H}_{\mathbf{a d s}}(\mathbf{k J} / \mathbf{m o l})$ & $-\Delta \mathbf{S}_{\mathbf{a d s}}(\mathbf{J} / \mathbf{m o l ~ K})$ & Ref. \\
\hline HKUST-1 & 15.2 & 61.7 & {$[32]$} \\
Ni-MOF-74 & 20.7 & 77.7 & {$[32]$} \\
UTSA-20 & 17.8 & 72.3 & {$[32]$} \\
PCN-14 & 11.4 & 47.39 & {$[32]$} \\
NJU-Bai-41 & 16.1 & 54.2 & {$[60]$} \\
\hline
\end{tabular}


Table 4. Cont.

\begin{tabular}{cccc}
\hline Framework & $-\Delta \mathbf{H}_{\mathbf{a d s}}(\mathbf{k J} / \mathbf{m o l})$ & $-\Delta \mathbf{S}_{\mathbf{a d s}}(\mathbf{J} / \mathbf{m o l ~ K})$ & Ref. \\
\hline MOF-905-Naph & 10.87 & 36.7 & {$[61]$} \\
MOF-905-NO $_{2}$ & 9.86 & 33.2 & {$[61]$} \\
MFM-300 (In) & 16.49 & 55.66 & {$[89]$} \\
ATC-Cu & 23.6 & 90.2 & {$[35]$} \\
MOF-520 & 14.0 & 47.1 & {$[65]$} \\
Al-soc-MOF-1 & 15.3 & 51.2 & {$[59]$} \\
MOF-519 & 14.1 & 47.2 & {$[65]$} \\
ZIF-68 & 16.7 & 61.2 & {$[74]$} \\
ZIF-69 & 18.4 & 61.8 & {$[74]$} \\
Cu-tbo-MOF-5 & 21.6 & 71.8 & {$[68]$} \\
NJU-Bai-19 & 14.7 & 49.4 & {$[67]$} \\
NJU-Bai-42 & 12.8 & 46.9 & {$[60]$} \\
NJU-Bai-41 & 14.4 & 48.3 & {$[60]$} \\
MOF-950 & 11.3 & 38.1 & {$[61]$} \\
\hline
\end{tabular}

The relationship between the enthalpy and entropy of adsorption of methane on MOFs was assessed (Figure 7). It was found that entropy and enthalpy of adsorption of methane on MOFs correlate. This was consistent with what was observed for the adsorption of hydrocarbons on zeolites [37]. Increasing enthalpy is associated with increasing entropy. This correlation was described as a compensation associated with an increasingly exothermic adsorption which is countered by decreasing entropy.

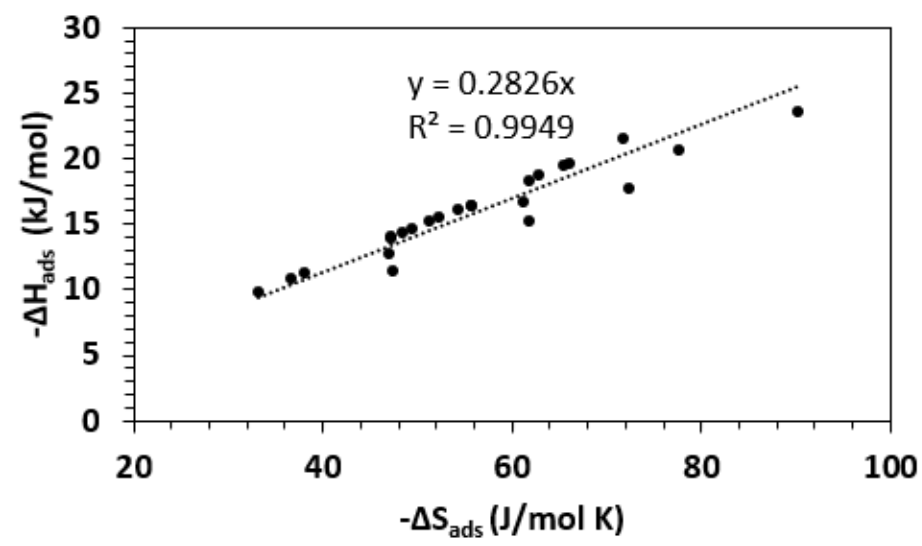

Figure 7. Relationship between $\Delta \mathrm{H}_{\mathrm{ads}}$ and $\Delta \mathrm{S}_{\mathrm{ads}}$ of methane for various MOFs from experiments. Each point represents a MOF whose enthalpy and entropy of adsorption was determined from experimental data at 1 bar.

In case of methane adsorption in zeolites and what is expected for MOFs, the maximum heat of adsorption corresponds to a pore diameter of $R=R c=2^{1 / 6} \sigma$, in which we have the maximum interactions of methane with the spherical shell. With increasing pore diameter from Rc, the heat of adsorption decreases. When decreasing the pore diameter from Rc, the interactions become repulsive and the magnitude of the enthalpy of adsorption quickly decreases until it becomes positive. The entropy loss upon adsorption increases with decreasing pore size. The entropy loss reaches its maximum when the methane molecule is frozen between the wall of the sphere.

According to Frost and Snurr, high gas adsorption could be achieved at ambient temperatures if the isosteric heat of adsorption could be increased for MOFs with large free volumes, but the negative impact for this theory was finding strategies for increasing the $Q_{\text {st }}$ without losses in free volume [90]. Frost and Snurr reported increasing the isosteric heat of adsorption helps to increase methane uptake [36]. By using the same theory, the optimal $Q_{\text {st }}$ in case of methane adsorption can be estimated. 
It was noticed when the Qst ${ }_{0}$ increased the storage capacity of MOFs which gives an idea of possibility for all MOFs structures to attain the capture target, assuming Qst ${ }_{0}$ is increased enough without the loss in free volume. Each MOF structure has an optimal Qst $_{0}$ which gives the maximum deliverable capacity. The optimal Qst was calculated as a function of entropy change relative to the standard pressure $P_{0}(1$ bar) (Figure 8$)$. With increasing entropy change relative to the standard pressure $\mathrm{P}_{0}(1 \mathrm{bar}), \mathrm{Q}_{\text {st }}$ decreased. Finally, it was concluded that materials creating with large surface area $\left(>4800 \mathrm{~m}^{2} / \mathrm{g}\right.$ ) and large $\mathrm{Q}_{\text {st }}$ values (around $20 \mathrm{~kJ} / \mathrm{mol}$ ) is potentially advantageous. While keeping the other variables the same, the $Q_{\text {st }}$ values increased. In case of real materials, the $Q_{s t}$ value can be increased by adding some heavy atoms to the structure or by reducing the free volume which reduced the gravimetric or volumetric capacities to some degree but increased the challenge of attaining this design target.

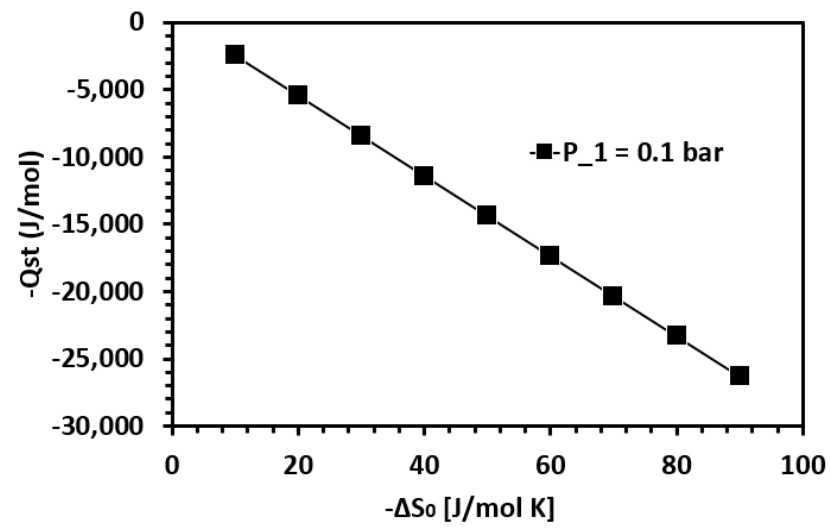

Figure 8. Optimal Qst as a function of the entropy change relative to the standard pressure $\mathrm{P}_{0}(1 \mathrm{bar})$.

In addition to the uptake capacity of the MOF for methane, the rate of desorption is important for this process in practice. The pre-exponential factor for the desorption of methane from porous materials was calculated. As shown in Equations (11) and (12) the pre-exponential factor depends on the rotational entropy and the 1-dimensional translational entropy. Because the translational entropy is a term, confinement effects. Therefore, the occupiable volume and pore diameter of the MOF effect the rate of methane desorption. The rate of methane desorption is important in this process because it indicates how long it will take to remove adsorbed methane after adsorption. This is important for the process to be cyclable. For methane desorption from a flat surface, the pre-exponential was calculated to be $6.2 \times 10^{12} \mathrm{~s}^{-1}$. The logarithm of the pre-exponential factor is shown in Figure 9 for methane desorption. The rate of desorption depends on the molecular size as well as the degrees of rotational freedom lost upon adsorption. As shown in Figure 4, the rotational degrees of freedom lost upon adsorption depends on the occupiable volume and therefore the pore structure of the MOF.

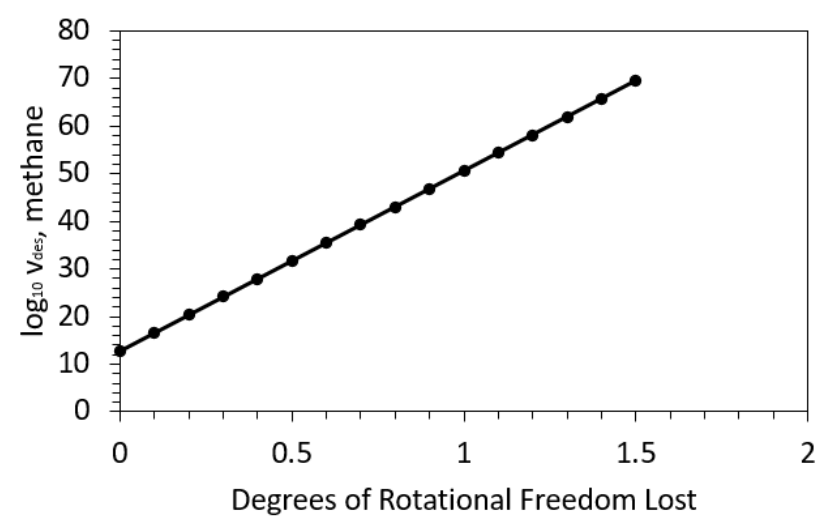

Figure 9. A plot of the logarithm of the pre-exponential factor of methane desorption against the degrees of rotational freedom lost upon adsorption. 


\section{Discussion}

Enhancing Volumetric Energy Density and Cyclability in MOFs for Global Methane Emissions Mitigation

In the case of global methane emissions, entropy is important to determine how much can adsorbed and how fast it can be adsorbed in the MOF. Van der Waals interaction forces between methane molecules and atoms of MOFs enable the physisorption of methane to yield a density greater than that of the gaseous methane at the same conditions. There is an enormous amount of research going on to improve the methane adsorption in MOFs by altering the frameworks which tunes the interaction between atoms and methane to achieve higher stored energy densities.

The results combined together of the entropy of adsorption of methane as well as the preexponential for desorption of methane provide a guideline with which to design MOFs for methane emissions abatement. One key component from both results is that the pore volume and pore structure of the MOF is key in determining the driving force for adsorption and how fast the desorption can occur. The larger the occupiable volume, the less the rotational degrees of freedom are decreased. This leads to a decrease in the magnitude of the entropy change of adsorption. With a decreased magnitude, the maximum equilibrium adsorption uptake of the MOF decreases. The more rotational degrees of freedom that are lost, the larger the pre-exponential factor for desorption. This is associated with an increased rate of desorption.

The most effective MOF for enhanced methane capture at 1 bar and $298 \mathrm{~K}$ possessed a nano-trap. It was designed by arranging coordinatively unsaturated metal centers oppositely adjacent to one another. This was coupled with the inclusion of a high density of alkyl groups. This increased the energetic favorability to have methane in the pore. The results in Tables 1 and 2 demonstrate that MOFs exhibited the best methane uptakes at 1 bar and $298 \mathrm{~K}$ as compared to other materials investigated such as carbonaceous materials and zeolites and are effective adsorbents. ATC-Cu, Cu-tbo-MOF-5, and HKUST-1 were found to be most effective for enhanced methane capture at $298 \mathrm{~K}$ and 1 bar.

The found differences between the MOFs can be related to the arrangement of coordinatively unsaturated metal centers and functional groups. In addition, a high heat of adsorption is also favorable for this application under these conditions. Interestingly, the best performing MOF for enhanced methane capture at $298 \mathrm{~K}$ and 1 bar contain copper. MOFs which have an inadequate overlap of the potential fields from opposite pore walls are not as effective at enhanced methane capture [35]. Ultra-high surface area is not as critical a property for enhanced methane capture as it is for MOFs designed for methane storage at 35-100 bar. MOFs that possess a nano-trap with high Qst, coordinatively unsaturated metal centers with a high density of functional groups are most promising for enhanced methane capture under these conditions.

It is also important to note that MOFs designed for methane storage for NGV do not always perform as well for methane emission mitigation. This is in part due to the fact that they have been designed to have low uptakes at pressures lower than 5 bar [60]. Therefore, design approach has to be altered for this application. Polarizability of methane, and functionality of MOF, and pore size need to be determined. There are a wide range of structures that can be made and the results here give an idea of the features for global methane emissions abatement. The results shown here assist in the design of MOFs for this application. From the pore structure the entropy change of adsorption can be calculated and related to Qst and desired pore structure of the MOF. From there, reticular chemistry can be used to design the MOF and test it at these conditions with some confidence and in a methodical manner. Furthermore, it was demonstrated that the entropy change of adsorption is directly related to the enthalpy change of adsorption, providing additional relationships that can be used to aid in the methodological design of MOFs for this application. The results are quantifiable and corroborated by experiments. 


\section{Conclusions}

Here, the use of MOFs for global methane emissions mitigation was investigated. It was generally concluded that MOFs are appropriate for use as effective adsorbents for methane capture at $298 \mathrm{~K}$ and 1 bar from experiments and a comparison of the obtained results with experimental investigation of other possible adsorbents demonstrated that they are excellent adsorbents. Particular focus was paid to confinement effect of methane and its effects on entropy. Entropy is important to calculate because it provides an idea of how much methane can be adsorbed at a specific temperature and pressure and how fast it can desorb for each MOF for global methane mitigation. It was found that methane was confined in the pores of MOFs leading to a restriction in molecular motion. Methane lost one degree of translational motion when adsorbed and rational motion depending on the degree of confinement. The entropy loss associated with adsorption was calculated considering the translation and rotational entropy of a methane molecule. Through investigation on various MOFs, it was discovered that a single descriptor is sufficient in predicting the loss of rotational motion. This was corroborated by experiments. Lastly, the pre-exponential factor associated with the rate of desorption of methane was calculated and found to vary orders of magnitude depending on molecular confinement in the pore. In this work, it was demonstrated that all the parameters from a structural descriptor of the MOF to the methane uptake and rate of desorption are directly related. Furthermore, the entropy change of adsorption was directly related to Qst and to pore size to to efficiently design MOFs using reticular chemistry for this application [19]. The best MOF has the following characteristics of a high Qst (greater than $20 \mathrm{~kJ} / \mathrm{mol}$ ) and optimum pore occupiable volume. The results of this work can be applied to more efficiently design materials for global methane mitigation and for other gas adsorption applications.

Funding: This research was funded by United Arab Emirates University, grant no G00002618.

Conflicts of Interest: The author declares no conflict of interest.

\section{References}

1. Etiope, G.; Schwietzke, S. Global geological methane emissions: An update of top-down and bottom-up estimates. Elem. Anthr. 2019, 7, 1-9. [CrossRef]

2. Schiermeier, Q. Global Methane Levels Soar to Record High. Available online: https://www.nature.com/ articles/d41586-020-02116-8 (accessed on 14 July 2020).

3. Hiroko Tabuchi Global Methane Emissions Reach a Record High. Available online: https://www.nytimes. com/2020/07/14/climate/methane-emissions-record.html (accessed on 15 July 2020).

4. Thurber, A.R.; Seabrook, S.; Welsh, R.M. Riddles in the cold: Antarctic endemism and microbial succession impact methane cycling in the Southern Ocean. Proc. R. Soc. B Biol. Sci. 2020, 287, 20201134. [CrossRef] [PubMed]

5. Clark, A.; Malik, N.S. No One Is Owning Up to Releasing Cloud of Methane in Florida. Available online: https://www.bloomberg.com/news/articles/2020-07-27/no-one-is-owning-up-to-releasing-cloud-ofmethane-in-florida (accessed on 18 August 2020).

6. Ferretti, D.F.; Miller, J.B.; White, J.W.C.; Etheridge, D.M.; Lassey, K.R.; Lowe, D.C.; MacFarling Meure, C.M.; Dreier, M.F.; Trudinger, C.M.; Van Ommen, T.D.; et al. Atmospheric science: Unexpected changes to the global methane budget over the past 2000 years. Science 2005, 309, 1714-1717. [CrossRef] [PubMed]

7. Neef, L.; Van Weele, M.; Van Velthoven, P. Optimal estimation of the present-day global methane budget. Global Biogeochem. Cycles 2010, 24,1-10. [CrossRef]

8. Mitchell, L.E.; Brook, E.J.; Sowers, T.; McConnell, J.R.; Taylor, K. Multidecadal variability of atmospheric methane, 1000-1800 C.E. J. Geophys. Res. Biogeosci. 2011, 116, 1-16. [CrossRef]

9. EPA's Voluntary Methane Programs for the Oil and Natural Gas Industry. Available online: https: //www.epa.gov/natural-gas-star-program (accessed on 8 February 2020).

10. Consumers Energy Methane Reduction Plan. Available online: https://s2.q4cdn.com/027997281/files/doc_ downloads/2019/11/CE-Methane-Report-2019-FINAL.PDF (accessed on 18 August 2020). 
11. Kate Abnett, S.N. EU's Greenhouse Gas Strategy Fails to Plug Methane Hole. Available online: https://www.reuters.com/article/us-eu-energy-methane-insight/eus-greenhouse-gas-strategy-fails-toplug-methane-hole-idUSKCN24I0IV (accessed on 19 August 2020).

12. Bui, M.; Adjiman, C.S.; Bardow, A.; Anthony, E.J.; Boston, A.; Brown, S.; Fennell, P.S.; Fuss, S.; Galindo, A.; Hackett, L.A.; et al. Carbon capture and storage (CCS): The way forward. Energy Environ. Sci. 2018, 11, 1062-1176. [CrossRef]

13. Schoedel, A.; Ji, Z.; Yaghi, O.M. The role of metal-organic frameworks in a carbon-neutral energy cycle. Nat. Energy 2016, 1, 1-13. [CrossRef]

14. Britt, D.; Furukawa, H.; Wang, B.; Glover, T.G.; Yaghi, O.M. Highly efficient separation of carbon dioxide by a metal-organic framework replete with open metal sites. Proc. Natl. Acad. Sci. USA 2009, 106, 20637-20640. [CrossRef]

15. Li, J.R.; Ma, Y.; McCarthy, M.C.; Sculley, J.; Yu, J.; Jeong, H.K.; Balbuena, P.B.; Zhou, H.C. Carbon dioxide capture-related gas adsorption and separation in metal-organic frameworks. Coord. Chem. Rev. 2011, 255, 1791-1823. [CrossRef]

16. Kim, E.J.; Siegelman, R.L.; Jiang, H.Z.H.; Forse, A.C.; Lee, J.-H.; Martell, J.D.; Milner, P.J.; Falkowski, J.M.; Neaton, J.B.; Reimer, J.A.; et al. Cooperative carbon capture and steam regeneration with tetraamine-appended metal-organic frameworks. Science 2020, 369, 392 LP-396.

17. Furukawa, H.; Cordova, K.E.; O'Keeffe, M.; Yaghi, O.M. The Chemistry and Applications of Metal-Organic Frameworks. Science 2013, 341, 1230444-1-1230444-13. [CrossRef] [PubMed]

18. Long, J.R.; Yaghi, O.M. The pervasive chemistry of metal-organic frameworks. Chem. Soc. Rev. 2009, 38, 1213-1214. [CrossRef] [PubMed]

19. Yaghi, O.M.; O’Keeffe, M.; Ockwig, N.W.; Chae, H.K.; Eddaoudi, M.; Kim, J. Reticular synthesis and the design of new materials. Nature 2003, 423, 705-714. [CrossRef] [PubMed]

20. Morris, R.E.; Wheatley, P.S. Gas storage in nanoporous materials. Angew. Chem. Int. Ed. 2008, 47, $4966-4981$. [CrossRef]

21. Makal, T.A.; Li, J.-R.R.; Lu, W.; Zhou, H.-C.C. Methane storage in advanced porous materials. Chem. Soc. Rev. 2012, 41, 7761-7779. [CrossRef]

22. He, Y.; Chen, F.; Li, B.; Qian, G.; Zhou, W.; Chen, B. Porous metal-organic frameworks for fuel storage. Coord. Chem. Rev. 2018, 373, 167-198. [CrossRef]

23. He, Y.; Zhou, W.; Qian, G.; Chen, B. Methane storage in metal-organic frameworks. Chem Soc Rev 2014, 43, 5657-5678. [CrossRef]

24. Li, X.; Yang, X.; Xue, H.; Pang, H.; Xu, Q. Metal-organic frameworks as a platform for clean energy applications. EnergyChem 2020, 1, 100006. [CrossRef]

25. Zhang, H.; Nai, J.; Yu, L.; Lou, X.W. (David) Metal-Organic-Framework-Based Materials as Platforms for Renewable Energy and Environmental Applications. Joule 2017, 1, 77-107. [CrossRef]

26. Furukawa, H.; Ko, N.; Go, Y.B.; Aratani, N.; Choi, S.B.; Choi, E.; Yazaydin, A.Ö.; Snurr, R.Q.; O’Keeffe, M.; Kim, J.; et al. Ultrahigh porosity in metal-organic frameworks. Science 2010, 329, 424-428. [CrossRef]

27. Perry, J.J.; Perman, J.A.; Zaworotko, M.J. Design and synthesis of metal-organic frameworks using metal-organic polyhedra as supermolecular building blocks. Chem. Soc. Rev. 2009, 38, 1400-1417. [CrossRef]

28. Wang, C.; Liu, D.; Lin, W. Metal-organic frameworks as a tunable platform for designing functional molecular materials. J. Am. Chem. Soc. 2013, 135, 13222-13234. [CrossRef]

29. Konstas, K.; Osl, T.; Yang, Y.; Batten, M.; Burke, N.; Hill, A.J.; Hill, M.R. Methane storage in metal organic frameworks. J. Mater. Chem. 2012, 22, 16698-16708. [CrossRef]

30. Zhou, W. Methane storage in porous metal-organic frameworks: Current records and future perspectives. Chem. Rec. 2010, 10, 200-204. [CrossRef]

31. Wu, H.; Zhou, W.; Yildirim, T. High-capacity methane storage in metal-organic frameworks M2(dhtp): The important role of open metal sites. J. Am. Chem. Soc. 2009, 131, 4995-5000. [CrossRef] [PubMed]

32. Peng, Y.; Krungleviciute, V.; Eryazici, I.; Hupp, J.T.; Farha, O.K.; Yildirim, T. Methane storage in metal-organic frameworks: Current records, surprise findings, and challenges. J. Am. Chem. Soc. 2013, 135, 11887-11894. [CrossRef] [PubMed] 
33. Getzschmann, J.; Senkovska, I.; Wallacher, D.; Tovar, M.; Fairen-Jimenez, D.; Düren, T.; Van Baten, J.M.; Krishna, R.; Kaskel, S. Methane storage mechanism in the metal-organic framework Cu 3(btc)2: An in situ neutron diffraction study. Microporous Mesoporous Mater. 2010, 136, 50-58. [CrossRef]

34. Rosi, N.L.; Eckert, J.; Eddaoudi, M.; Vodak, D.T.; Kim, J.; O'Keeffe, M.; Yaghi, O.M. Hydrogen storage in microporous metal-organic frameworks. Science 2003, 300, 1127-1129. [CrossRef]

35. Niu, Z.; Cui, X.; Pham, T.; Lan, P.C.; Xing, H.; Forrest, K.A.; Wojtas, L.; Space, B.; Ma, S. A Metal-Organic Framework Based Methane Nano-trap for the Capture of Coal-Mine Methane. Angew. Chem. Int. Ed. 2019, 58, 10138-10141. [CrossRef]

36. Bhatia, S.K.; Myers, A.L. Optimum conditions for adsorptive storage. Langmuir 2006, 22, $1688-1700$. [CrossRef]

37. Dauenhauer, P.J.; Abdelrahman, O.A. A Universal Descriptor for the Entropy of Adsorbed Molecules in Confined Spaces. ACS Cent. Sci. 2018, 4, 1235-1243. [CrossRef]

38. Campbell, C.T.; Sellers, J.R. V The Entropies of Adsorbed Molecules. J. Am. Chem. Soc. 2012, 134, $18109-18115$. [CrossRef]

39. Liu, L.; Konstas, K.; Hill, M.R.; Telfer, S.G. Programmed pore architectures in modular quaternary metal-organic frameworks. J. Am. Chem. Soc. 2013, 135, 17731-17734. [CrossRef] [PubMed]

40. Guo, Z.; Wu, H.; Srinivas, G.; Zhou, Y.; Xiang, S.; Chen, Z.; Yang, Y.; Zhou, W.; O’Keeffe, M.; Chen, B. A metal-organic framework with optimized open metal sites and pore spaces for high methane storage at room temperature. Angew. Chem. Int. Ed. 2011, 50, 3178-3181. [CrossRef] [PubMed]

41. Kalidindi, S.B.; Nayak, S.; Briggs, M.E.; Jansat, S.; Katsoulidis, A.P.; Miller, G.J.; Warren, J.E.; Antypov, D.; Corà, F.; Slater, B.; et al. Chemical and structural stability of zirconium-based metal-organic frameworks with large three-dimensional pores by linker engineering. Angew. Chem. Int. Ed. 2015, 54, 221-226. [CrossRef] [PubMed]

42. Karagiaridi, O.; Bury, W.; Mondloch, J.E.; Hupp, J.T.; Farha, O.K. Solvent-assisted linker exchange: An alternative to the de novo synthesis of unattainable metal-organic frameworks. Angew. Chem. Int. Ed. 2014, 53, 4530-4540. [CrossRef]

43. Stock, N.; Biswas, S. Synthesis of metal-organic frameworks (MOFs): Routes to various MOF topologies, morphologies, and composites. Chem. Rev. 2012, 112, 933-969. [CrossRef]

44. Deng, H.; Doonan, C.J.; Furukawa, H.; Ferreira, R.B.; Towne, J.; Knobler, C.B.; Wang, B.; Yaghi, O.M. Multiple functional groups of varying ratios in metal-organic frameworks. Science 2010, 327, 846-850. [CrossRef]

45. Moghadam, P.Z.; Fairen-Jimenez, D.; Snurr, R.Q. Efficient identification of hydrophobic MOFs: Application in the capture of toxic industrial chemicals. J. Mater. Chem. A 2015, 4, 529-536. [CrossRef]

46. Casco, M.E.; Rey, F.; Jordá, J.L.; Rudić, S.; Fauth, F.; Martínez-Escandell, M.; Rodríguez-Reinoso, F.; Ramos-Fernández, E.V.; Silvestre-Albero, J. Paving the way for methane hydrate formation on metal-organic frameworks (MOFs). Chem. Sci. 2016, 7, 3658-3666. [CrossRef]

47. Almeida Paz, F.A.; Klinowski, J.; Vilela, S.M.F.; Tomé, J.P.C.; Cavaleiro, J.A.S.; Rocha, J. Ligand design for functional metal-organic frameworks. Chem. Soc. Rev. 2012, 41, 1088-1110. [CrossRef] [PubMed]

48. Zhao, D.; Timmons, D.J.; Yuan, D.; Zhou, H.C. Tuning the topology and functionality of metal-organic frameworks by ligand design. Acc. Chem. Res. 2011, 44, 123-133. [CrossRef] [PubMed]

49. Walecka, J.D. Introduction to Statistical Mechanics; World Scientific: Singapore, 2011; ISBN 9789814366229.

50. Donnelly, P.; Ellis, R.S. Entropy, Large Deviations, and Statistical Mechanics. J. Am. Stat. Assoc. 1987, 82, 948-949. [CrossRef]

51. Dudko, O.K. Statistical Mechanics: Entropy, Order Parameters, and Complexity; Springer Nature: Cham, Switzerland, 2007.

52. Lozano-Castelló, D.; Cazorla-Amorós, D.; Linares-Solano, A.; Quinn, D.F. Influence of pore size distribution on methane storage at relatively low pressure: Preparation of activated carbon with optimum pore size. Carbon N. Y. 2002, 40, 989-1002. [CrossRef]

53. Policicchio, A.; MacCallini, E.; Agostino, R.G.; Ciuchi, F.; Aloise, A.; Giordano, G. Higher methane storage at low pressure and room temperature in new easily scalable large-scale production activated carbon for static and vehicular applications. Fuel 2013, 104, 813-821. [CrossRef]

54. Wood, C.D.; Tan, B.; Trewin, A.; Su, F.; Rosseinsky, M.J.; Bradshaw, D.; Sun, Y.; Zhou, L.; Cooper, A.I. Microporous organic polymers for methane storage. Adv. Mater. 2008, 20, 1916-1920. [CrossRef] 
55. Li, Y.; Yi, H.; Tang, X.; Li, F.; Yuan, Q. Adsorption separation of CO2/CH4 gas mixture on the commercial zeolites at atmospheric pressure. Chem. Eng. J. 2013, 229, 50-56. [CrossRef]

56. Wen, H.M.; Li, B.; Li, L.; Lin, R.B.; Zhou, W.; Qian, G.; Chen, B. A Metal-Organic Framework with Optimized Porosity and Functional Sites for High Gravimetric and Volumetric Methane Storage Working Capacities. Adv. Mater. 2018, 30, 1704792. [CrossRef]

57. Moellmer, J.; Moeller, A.; Dreisbach, F.; Glaeser, R.; Staudt, R. High pressure adsorption of hydrogen, nitrogen, carbon dioxide and methane on the metal-organic framework HKUST-1. Microporous Mesoporous Mater. 2011, 138, 140-148. [CrossRef]

58. Chen, Z.; Li, P.; Anderson, R.; Wang, X.; Zhang, X.; Robison, L.; Redfern, L.R.; Moribe, S.; Islamoglu, T.; Gómez-Gualdrón, D.A.; et al. Balancing volumetric and gravimetric uptake in highly porous materials for clean energy. Science 2020, 368, 297 LP-303. [CrossRef]

59. Alezi, D.; Belmabkhout, Y.; Suyetin, M.; Bhatt, P.M.; Weseliński, L.J.; Solovyeva, V.; Adil, K.; Spanopoulos, I.; Trikalitis, P.N.; Emwas, A.H.; et al. MOF Crystal Chemistry Paving the Way to Gas Storage Needs: Aluminum-Based soc -MOF for CH4, O2, and CO2 Storage. J. Am. Chem. Soc. 2015, 137, 13308-13318. [CrossRef] [PubMed]

60. Zhang, M.; Zhou, W.; Pham, T.; Forrest, K.A.; Liu, W.; He, Y.; Wu, H.; Yildirim, T.; Chen, B.; Space, B.; et al. Fine Tuning of MOF-505 Analogues To Reduce Low-Pressure Methane Uptake and Enhance Methane Working Capacity. Angew. Chem. Int. Ed. 2017, 56, 11426-11430. [CrossRef]

61. Jiang, J.; Furukawa, H.; Zhang, Y.B.; Yaghi, O.M. High Methane Storage Working Capacity in Metal-Organic Frameworks with Acrylate Links. J. Am. Chem. Soc. 2016, 138, 10244-10251. [CrossRef]

62. Mason, J.A.; Oktawiec, J.; Taylor, M.K.; Hudson, M.R.; Rodriguez, J.; Bachman, J.E.; Gonzalez, M.I.; Cervellino, A.; Guagliardi, A.; Brown, C.M.; et al. Methane storage in flexible metal-organic frameworks with intrinsic thermal management. Nature 2015, 527, 357-361. [CrossRef] [PubMed]

63. Li, L.; Tang, S.; Wang, C.; Lv, X.; Jiang, M.; Wu, H.; Zhao, X. High gas storage capacities and stepwise adsorption in a UiO type metal-organic framework incorporating Lewis basic bipyridyl sites. Chem. Commun. 2014, 50, 2304-2307. [CrossRef] [PubMed]

64. Wilmer, C.E.; Farha, O.K.; Yildirim, T.; Eryazici, I.; Krungleviciute, V.; Sarjeant, A.A.; Snurr, R.Q.; Hupp, J.T. Gram-scale, high-yield synthesis of a robust metal-organic framework for storing methane and other gases. Energy Environ. Sci. 2013, 6, 1158-1163. [CrossRef]

65. Gándara, F.; Furukawa, H.; Lee, S.; Yaghi, O.M. High methane storage capacity in aluminum metal-organic frameworks. J. Am. Chem. Soc. 2014, 136, 5271-5274. [CrossRef] [PubMed]

66. Mason, J.A.; Veenstra, M.; Long, J.R. Evaluating metal-organic frameworks for natural gas storage. Chem. Sci. 2014, 5, 32-51. [CrossRef]

67. Zhang, M.; Chen, C.; Wang, Q.; Fu, W.; Huang, K.; Zhou, W. A metal-organic framework functionalized with piperazine exhibiting enhanced CH4 storage. J. Mater. Chem. A 2017, 5, 349-354. [CrossRef]

68. Spanopoulos, I.; Tsangarakis, C.; Klontzas, E.; Tylianakis, E.; Froudakis, G.; Adil, K.; Belmabkhout, Y.; Eddaoudi, M.; Trikalitis, P.N. Reticular Synthesis of HKUST-like tbo-MOFs with Enhanced CH4 Storage. J. Am. Chem. Soc. 2016, 138, 1568-1574. [CrossRef]

69. Volkringer, C.; Loiseau, T.; Haouas, M.; Taulelle, F.; Popov, D.; Burghammer, M.; Riekel, C.; Zlotea, C.; Cuevas, F.; Latroche, M.; et al. Occurrence of Uncommon Infinite Chains Consisting of Edge-Sharing Octahedra in a Porous Metal Organic Framework-Type Aluminum Pyromellitate Al4 $(\mathrm{OH}) 8[\mathrm{C} 10 \mathrm{O} 8 \mathrm{H} 2]$ (MIL-120): Synthesis, Structure, and Gas Sorption Properties. Chem. Mater. 2009, 21, 5783-5791. [CrossRef]

70. Zhuang, W.; Yuan, D.; Liu, D.; Zhong, C.; Li, J.-R.; Zhou, H.-C. Robust Metal-Organic Framework with An Octatopic Ligand for Gas Adsorption and Separation: Combined Characterization by Experiments and Molecular Simulation. Chem. Mater. 2012, 24, 18-25. [CrossRef]

71. Hu, Y.; Xiang, S.; Zhang, W.; Zhang, Z.; Wang, L.; Bai, J.; Chen, B. A new MOF-505 analog exhibiting high acetylene storage. Chem. Commun. 2009, 7551-7553. [CrossRef] [PubMed]

72. Cheon, Y.E.; Park, J.; Suh, M.P. Selective gas adsorption in a magnesium-based metal-organic framework. Chem. Commun. 2009, 5436-5438. [CrossRef] [PubMed]

73. Hayashi, H.; Côté, A.P.; Furukawa, H.; O’Keeffe, M.; Yaghi, O.M. Zeolite A imidazolate frameworks. Nat. Mater. 2007, 6, 501-506. [CrossRef] [PubMed] 
74. Banerjee, R.; Furukawa, H.; Britt, D.; Knobler, C.; O’Keeffe, M.; Yaghi, O.M. Control of pore size and functionality in isoreticular zeolitic imidazolate frameworks and their carbon dioxide selective capture properties. J. Am. Chem. Soc. 2009, 132, 5578-5579. [CrossRef] [PubMed]

75. Neofotistou, E.; Malliakas, C.D.; Trikalitis, P.N. Unprecedented sulfone-functionalized metal-organic frameworks and gas-sorption properties. Chem. A Eur. J. 2009, 15, 4523-4527. [CrossRef]

76. Yoon, J.W.; Jhung, S.H.; Hwang, Y.K.; Humphrey, S.M.; Wood, P.T.; Chang, J.-S. Gas-Sorption Selectivity of CUK-1: A Porous Coordination Solid Made of Cobalt(II) and Pyridine-2,4- Dicarboxylic Acid. Adv. Mater. 2007, 19, 1830-1834. [CrossRef]

77. Moon, H.R.; Kobayashi, N.; Suh, M.P. Porous Metal-Organic Framework with Coordinatively Unsaturated MnII Sites:Sorption Properties for Various Gases. Inorg. Chem. 2006, 45, 8672-8676. [CrossRef]

78. Zhang, S.-M.; Chang, Z.; Hu, T.-L.; Bu, X.-H. New Three-Dimensional Porous Metal Organic Framework with Tetrazole Functionalized Aromatic Carboxylic Acid: Synthesis, Structure, and Gas Adsorption Properties. Inorg. Chem. 2010, 49, 11581-11586. [CrossRef]

79. Chen, Z.; Xiang, S.; Arman, H.D.; Li, P.; Tidrow, S.; Zhao, D.; Chen, B. A microporous metal-organic framework with immobilized $-\mathrm{OH}$ functional groups within the pore surfaces for selective gas sorption. Eur. J. Inorg. Chem. 2010, 2010, 3745-3749. [CrossRef]

80. Zhang, Z.; Xiang, S.; Chen, Y.-S.; Ma, S.; Lee, Y.; Phely-Bobin, T.; Chen, B. A Robust Highly Interpenetrated Metal-Organic Framework Constructed from Pentanuclear Clusters for Selective Sorption of Gas Molecules. Inorg. Chem. 2010, 49, 8444-8448. [CrossRef] [PubMed]

81. Zhang, Z.; Xiang, S.; Rao, X.; Zheng, Q.; Fronczek, F.R.; Qian, G.; Chen, B. A rod packing microporous metal-organic framework with open metal sites for selective guest sorption and sensing of nitrobenzene. Chem. Commun. 2010, 46, 7205-7207. [CrossRef] [PubMed]

82. Li, H.; Shi, W.; Zhao, K.; Niu, Z.; Chen, X.; Cheng, P. A Robust Porous Metal-Organic Framework with a New Topology That Demonstrates Pronounced Porosity and High-Efficiency Sorption/Selectivity Properties of Small Molecules. Chem. A Eur. J. 2012, 18, 5715-5723. [CrossRef] [PubMed]

83. Kang, Z.; Xue, M.; Zhang, D.; Fan, L.; Pan, Y.; Qiu, S. Hybrid metal-organic framework nanomaterials with enhanced carbon dioxide and methane adsorption enthalpy by incorporation of carbon nanotubes. Inorg. Chem. Commun. 2015, 58, 79-83. [CrossRef]

84. Lozano-Castelló, D.; Alcañiz-Monge, J.; De La Casa-Lillo, M.A.; Cazorla-Amorós, D.; Linares-Solano, A. Advances in the study of methane storage in porous carbonaceous materials. Fuel 2002, 81, 1777-1803. [CrossRef]

85. Kubota, Y.; Takata, M.; Kitaura, R.; Matsuda, R.; Kobayashi, T.C.; Kitagawa, S. Hindered Rotation of Methane Molecules in the One-Dimensional Nanochannel of a Porous Coordination Polymer. J. Nanosci. Nanotechnol. 2009, 9, 69-76. [CrossRef]

86. Chung, Y.G.; Camp, J.; Haranczyk, M.; Sikora, B.J.; Bury, W.; Krungleviciute, V.; Yildirim, T.; Farha, O.K.; Sholl, D.S.; Snurr, R.Q. Computation-ready, experimental metal-organic frameworks: A tool to enable high-throughput screening of nanoporous crystals. Chem. Mater. 2014, 26, 6185-6192. [CrossRef]

87. Zhao, D.; Yuan, D.; Yakovenko, A.; Zhou, H.-C. A NbO-type metal-organic framework derived from a polyyne-coupled di-isophthalate linker formed in situ. Chem. Commun. 2010, 46, 4196-4198. [CrossRef] [PubMed]

88. Park, H.J.; Cheon, Y.E.; Suh, M.P. Post-Synthetic Reversible Incorporation of Organic Linkers into Porous Metal-Organic Frameworks through Single-Crystal-to-Single-Crystal Transformations and Modification of Gas-Sorption Properties. Chem. A Eur. J. 2010, 16, 11662-11669. [CrossRef]

89. Savage, M.; da Silva, I.; Johnson, M.; Carter, J.H.; Newby, R.; Suyetin, M.; Besley, E.; Manuel, P.; Rudić, S.; Fitch, A.N.; et al. Observation of Binding and Rotation of Methane and Hydrogen within a Functional Metal-Organic Framework. J. Am. Chem. Soc. 2016, 138, 9119-9127. [CrossRef] [PubMed]

90. Lee, S.J.; Bae, Y.S. Can metal-organic frameworks attain new DOE targets for on-board methane storage by increasing methane heat of adsorption? J. Phys. Chem. C 2014, 118, 19833-19841. [CrossRef]

Publisher's Note: MDPI stays neutral with regard to jurisdictional claims in published maps and institutional affiliations. 